\title{
DE DUENDES ENAMORADOS. TRATAMIENTO TRADICIONAL DE UN MOTIVO EN UN CASO RECOGIDO POR EL SANTO OFICIO NOVOHISPANO ${ }^{1}$
}

\author{
Claudia Carranza \\ El Colegio de San Luis - México \\ claudia.carranza@colsan.edu.mx
}

ntre los expedientes del Santo Oficio de la Nueva España no son pocos los casos que se registran sobre duendes y sus apariciones en diferentes geografías de América. Uno de ellos, recogido en el siglo XVIII, da cuenta del testimonio de María de la Trinidad, mujer avecindada en Guatemala quien afirmaba que un duende la seguía y se comunicaba con ella. El caso se conforma de los elementos narrativos y discursivos que suelen caracterizar a los diminutos personajes y las historias que en torno a ellos se producen, pero sobre todo también subraya la situación desesperada en la que se veía la mujer de ciertos grupos en la época.

Los duendes son seres ambiguos cuya definición circula entre el paganismo y la demonología, lo que probablemente ha provocado que en ocasiones se les otorgue la atención curiosa o bien la negación ante el temor de una posible invocación. Coincido con José Manuel Pedrosa cuando señala que son

como todo el mundo sabe, personajes instalados sobre todo en el imaginario popular, en los márgenes de la cultura oficial y de la religión institucional. No muestran el currículum legítimamente abultado del demonio, ni las funciones ejemplarizantes —a veces plenamente aprovechables para los usos religiosos

1 Este artículo se ha desarrollado dentro del proyecto «La mujer frente a la Inquisición española y novohispana» (FEM2016-78192-P), I+D de Excelencia del Ministerio de Economía y Competitividad (MINECO), financiado por la Agencia Estatal de Investigación (AEI) y el Fondo Europeo de Desarrollo Regional (FEDER, UE); y del grupo de investigación «Mentalidades mágicas y discursos antisupersticiosos (siglos XVI, XVII y XVIII)», grupo consolidado por la Universidad Autónoma de Madrid.

Edad de Oro, XXXVIII (2019), pp. 263-279, ISSN: 0212-0429 - ISSNe: 2605-3314

DOI http://doi.org/10.15366/edadoro2019.38.014 
ortodoxos - que se podía dar a los fantasmas o a las ánimas en pena. Los duendes son criaturas más variables, más fugaces, menos previsibles. También menos poderosas, más menudas y, por tanto, menos inquietantes. Con los duendes nunca supieron muy bien qué hacer los teólogos, los filósofos, los naturalistas de antaño (2006b: 110).

Han sido pocos los que se han atrevido a desmenuzar a estos seres, con más frecuencia se ha preferido catalogarlos y dar cuenta de sus apariciones, o bien describirlos, por lo regular con una actitud insegura, titubeante, mezclándolos con otros monstruos, o bien protegiéndolos bajo un imaginario sostenido por la tradición.

El único, en el ámbito hispánico, que intentó con seriedad hablar de ellos fue fray Antonio de Fuentelapeña a mediados del siglo XVII, uno de los últimos tratadistas que seguía la línea de otros tantos autores de misceláneas renacentistas, como Torquemada o Pedro Mexía. Este autor dedicó un amplio tratado al nacimiento de los duendes, a su calificación y a su explicación. Su ensayo, titulado el Ente dilucidado, puede verse como una obra de la crisis, y aquí vuelvo a citar a José Manuel Pedrosa cuando dice que:

Sobre todo, porque se trata de uno de los últimos intentos sistemáticos que emprendieron los intelectuales que se resistían a entrar en la modernidad de apuntalar su mundo mágico y sobrenatural, voluntariosamente sostenido sobre los pilares de la fe, ante los avances desestabilizadores de la razón y de la ciencia que se dibujaban ya en el horizonte. Un intento de reforzarlo, paradójicamente, con los instrumentos de la razón, o de lo que se pretendía que era la razón, si por tal puede entenderse — pues se trataba, en realidad, de una especie de imaginada razón tomista de raíz medieval— la acumulación de «pruebas» y de más «pruebas» como aquellas con las que Fuentelapeña aspiraba a probar justamente los fenómenos más improbables que pueda haber (2006b: 110).

Fuentelapeña, como señala Pedrosa, intentaba por todos los medios diseccionar lo inasible, por lo menos en el espacio físico, es decir, se introduce en un campo metafísico - de hecho uno de los puntos que aborda en su tratado es la posibilidad de que los duendes sean ángeles o demonios- , pero tratando de ajustarlo a la realidad sin contar con más pruebas que lo que lo que había escuchado sobre el tema, lo que había leído, etc. De este modo, el autor introduce sus conclusiones con convicción, basándose en autoridades que durante siglos sirvieron de sostén a muchos otros libros, entre ellos, las misceláneas, que trataban de explicar asuntos extraordinarios, verdaderos compendios de mirabillia, garantizando su veracidad a partir de la mención de grandes autores desde la época clásica hasta los primeros autores cristianos. En este sentido, no es extraño que en la mayor parte de los 
textos renacentistas se reproduzcan creencias y mundos paganos, que además difícilmente podían ser contrarrestados a falta de un conocimiento insuficiente del mundo. Como señala Joaquín Rubio Tovar

el mundo aún se extiende en los terrenos de la más pura invención de un espacio en el que nace y se cobija lo maravilloso que tan claramente se expresa en algunos libros de viajes, de caballería, en algunas descripciones de la tierra. Los monstruos, los seres híbridos entre el hombre y el animal se cobijaban en un espacio alejado, en la zona del Índico. Cuando esta zona se recorrió, lo maravilloso se retiró a las ínsulas (1994: 122).

Fuentelapeña se repliega tras los testimonios orales, las historias de conocidos, amigos o a las «consejas de viejas», como también llama las historias y leyendas que conociera respecto al tema, lo que le proporciona pocas bases a un libro que pretende ser rigurosamente científico. Así, para muestra de su forma de trabajo, basta citar el inicio de la sección tercera del Ente, en la que el autor introduce las premisas en las que fundamentará sus argumentos respecto a la existencia y características de los duendes:

Supongo $[\ldots]$ que hay duendes, trasgos o fantasmas. Esta suposición parece no se puede negar, ya por los muchos autores que lo suponen así, verbi gratia, Olao Magno, arzobispo de Upsala, en el reino de Suecia y Gotia, en su Historia de las cosas septentrionales, el licenciado Salvador Ardevines Isla, médico, en su Fábrica universal del mundo mayor y menor, el padre don Antonio Lepari en sus Liciones Sacras y otros muchos, ya por las muchas personas que deponen haberlos sentido en diversas casas o percibido sus efectos, y ya por la deposición de otras muchas que, como testigos oculares, deponen haberlos visto siendo niños.

546.- Supongo [...] que a estos duendes en Castilla les llaman trasgos, en Cataluña folletos, que quiere decir espiritus locos, y en Italia farfareli, como lo tiene ubi supra dicho Salvador Ardevines, y en las partes septentrionales los llaman fantasmas, según Olao Magno citado, con otros que cita.

547.- Supongo [...] que estos duendes de que hablamos y que decimos se sienten en las casas, nunca hacen mal a nadie; siéntese su ruido, sin percibirse de ordinario el autor dél, quitan y ponen platos, juegan a los bolos, tiran chinitas, aficiónanse a los niños más que a los grandes, y especialmente se hallan duendes, que se aficionan a los caballos (Fuentelapeña 2006: 243).

El fraile, como podemos apreciar, articula su estudio a partir de autores conocidísimos por los tratadistas de la época, pero no puede y no debe evitar hacer un recuento de las creencias, de la tradición oral y finalmente de un suceso contado por una tercera persona que al final termina por citar como prueba de su argumentación: 
En Milán es esto cosa muy sabida y experimentada; y un capitán me certificó a mí, que en sólo su compañía había tres que cuidaban de tres caballos, y que el suyo tenía un duende muy su apasionado, que le hacía las crines, le echaba de comer, y cuidaba mucho de su regalo y adorno; experimento, que dejando registrada la cebada y bien cerrada la caballería, echaba la cebada menos, el caballo almohazado e inclinado de una forma extravagante y poco artificiosa, y que quitándole las crines al caballo, reconocía que lo debía de sentir el duende y amenazar al caballo, como haciendo sentimiento se dejase quitar el adorno que él le había puesto, infería lo de ver que el caballo se espantaba en dicho caso, sin ver el capitán la causa de dicho espanto (Fuentelapeña 2006: 244).

El verdadero espacio de acción de los duendes parece ser el de la tradición oral, y bien lo comprendió Feijóo en el discurso cuarto del tomo III, en donde dedica buena parte de sus argumentos a la explicación de la trayectoria que tienen las historias de duendes, la manera en la que se generan a partir de ruidos nocturnos, de apariciones de candelas, muchas veces producidas por efecto de animales, personas o cosas, pero que acaba dando entrada a las historias, las cuales, dice el ilustrado fraile, pueden deberse primero a la cobardía que se forja en una noche oscura que solo se explica en la narrativa de la leyenda. Después, la defensa de los hechos se termina convirtiendo en una causa de honor para el protagonista. La exclamación de Feijóo: «¡Oh, cuántos hurtos, cuántos estupros, y adulterios se han cometido, cubriéndose, o los agresores, o los medianeros, con la capa de Duendes!» (1998: 79), se fundamenta en estos sucesos que se confunden con duendes.

Es este equívoco, y los sucesos enumerados arriba, los que permitieron desarrollar el argumento de La dama Duende de Calderón de la Barca, en la cual el disfraz funciona para fomentar el amor entre doña Ángela y don Manuel, quien constantemente duda respecto a la corporeidad de una mujer que emplea las estrategias de un duende:

\begin{tabular}{|c|c|c|}
\hline Don Manuel. & $\begin{array}{l}\text { ¿No sabremos finalmente } \\
\text { de dónde nace este engaño? } \\
\text { ¡Cosme, Cosme! Vive el cielo, } \\
\text { que toco con las paredes; } \\
\text { ¿yo no hablaba aquí con él?, } \\
\text { ¿dónde se desaparece } \\
\text { tan presto?, ¿no estaba aquí? } \\
\text { Yo he de perder dignamente } \\
\text { el juicio, mas, pues es fuerza } \\
\text { que aquí otro cualquiera entre, } \\
\text { he de averiguar por dónde; } \\
\text { porque tengo de esconderme } \\
\text { en esta alcoba, y estar }\end{array}$ & 345 \\
\hline
\end{tabular}


esperando atentamente, hasta averiguar quién es esta hermosa Dama Duende

(Calderón de la Barca 2000: II, 217v)

A través de Cosme, gracioso de la obra, Calderón de la Barca expone algunos de los principales motivos y creencias en torno a los duendes, por ejemplo, las travesuras de mover muebles o bien de apagar candelas, cuando no uno de los motivos más recurrentes atribuidos a estos personajes: la transformación de tesoros en carbones²:

Mas ¿qué veo? Vive Dios

que en carbones lo convierte.

Duendecillo, duendecillo,

quien quiera que fuiste y eres,

el dinero que tú das

en lo que mandares vuelve,

mas, lo que yo hurto, ¿por qué?

(Calderón de la Barca 2000: I, 202v)

Cosme tiene su contraparte en la voz de don Manuel, quien suele criticar y reconvenir al criado, aunque en episodios como el arriba citado, también duda respecto a la veracidad de las creencias. Feijóo sigue la misma línea del drama calderoniano, cuando concluye:

Lo mismo digo de otra opinión vulgar, no menos ridícula: conviene a saber, que suelen los Duendes asociarse a determinadas personas. Dicen que se ha experimentado muchas veces que al tiempo que entra alguna persona en una casa, entra el Duende en ella, y en saliendo aquella, se va también el Duende. ¡Notable sinceridad! Yo creo que el caso que dio motivo a este error, sucedió, y sucede muchas veces. Entra una criada (o criado) en una casa a servir, y entra el Duende; sale la criada, y sale el Duende. ¿Por qué? Porque ella misma era el Duende, o lo era algún pícaro por motivo de ella. Acaeció muy poco ha en la Corte un suceso de este género, cuya verdad averiguó cierto amigo mío, confesándosela, movida de algún interés, la criada misma que había hecho el papel de Duende, y había puesto en notable confusión, no sólo la casa donde servía, mas aun todo el barrio. La comedia de La Dama Duende se representa más veces que se piensa, porque hay muchas damas que son Duendes; como también muchos que se hacen Duendes por las damas (1998: 79).

\footnotetext{
2 Covarrubias, por ejemplo, ya hablaba de los «tesoro de duendes» refiriéndose a «la hazienda que todo se consume y se deshaze sin saber en qué se ha gastado» (Tesoro..., s.v. «duende»).
} 
Feijóo niega a los duendes en una dura crítica contra Fuentelapeña. De existir estos seres, acepta el ilustrado con cautela, solo podrían ser espíritus familiares, demonios. El fraile, sin embargo, termina comprobando que el duende es en gran medida un elemento narrativo y se deja llevar por el placer de contar una historia para ejemplificar su argumentación:

Nuestro famoso Abad Juan Tritemio en la Crónica del Monasterio Hirsaugiense, cuenta que hubo en el Obispado de Hildesheim, en Sajonia, un Duende celebérrimo, llamado Hudequin. Era conocido de toda la comarca, porque frecuentemente se aparecía, ya a unos, ya a otros en traje de paisano, y otras veces hablaba, y conversaba sin que le viesen; mas su residencia principal era en la cocina del Obispo de aquella Diócesi, donde hacía con muy buena gracia todos los servicios que le encargaban, y se mostraba siempre muy oficioso con los que le trataban con agrado; pero vengativo, cruel, implacable con los que le ofendían. Sucedió que un día un muchacho de los que servían en la cocina le dijo muchas injurias. Quejóse Hudequin del agravio al Jefe de cocina para que le diese satisfacción. Viendo que no se hacía caso de su queja, mató al muchacho que le había injuriado, y dividiendo su cuerpo en trozos, los asó al fuego, y esparció por la cocina. Ni aun se satisfizo con esta crueldad su saña. Cuanto había servido antes a los Oficiales de la cocina, tanto los molestaba después, y no sólo a estos, pero a otros muchos del Palacio Episcopal, y de la Ciudad; de modo que parecía que aquella ofensa le había mudado enteramente la índole (Feijóo 1998: 82).

Como se ve, el duende es un espíritu constante hasta la necedad. Alrededor de estos seres se han escrito millares de folios, algunos de testimonios, otros de ficción, de los cuales ha habido registro en muchas épocas, en diferentes culturas de la mayor parte del mundo, en formatos que llegan hasta nuestros días, en el cine y la televisión.

Se trata de un personaje que se ubica entre los dioses paganos o los seres feéricos, dependiendo de la cultura en la que se encuentre. Como tales fueron entendidos incluso hasta el siglo XvII. Una de las muchas definiciones de la palabra duende los asocia con la voz dueño. Corominas lo describe como el «espíritu travieso, que se aparece fugazmente», por lo común, «el espíritu que se cree habita en una casa» (Breve diccionario... s.v. «duende») ${ }^{3}$. Esto se mantiene en el Diccionario de Autoridades, que lo cita como «el trasgo u demonio, que por infestar ordinariamente las casas, se llama así»».

3 Se considera que proviene de la palabra dueño por su raíz, que «es contracción de dueño de casa» (Breve diccionario... s.v. «duende»).

4 En la actualidad, la voz se define en el Diccionario de la Lengua Española, como el «Espíritu fantástico del que se dice que habita en algunas casas y que travesea, causando en ellas trastorno y estruendo. Aparece con figura de viejo o de niño en las narraciones tradicionales». 
Se describen como animales, dragones, serpientes incluso; sin embargo, en la mayor parte de los relatos aparecen como seres de estatura diminuta, en ocasiones se pintan como niños desnudos o con diferentes edades y diferentes vestidos, pueden o no tener cuernos. Coinciden, en muchos casos, las descripciones de capuchas o de sombreros como parte de su vestimenta habitual, que de alguna manera han permitido asociar a estos personajes con, entre otros Robin Goodfellow, como espíritu de los bosques (Hernández Sotelo 2017: 141-174). La variedad de seres feéricos no parece más que multiplicarse durante la Edad Media hasta que el cristianismo empezó a confundir y mezclar algunas de las razas feéricas y mitológicas bajo nombres más genéricos que fueron quedándose en el imaginario, tales como elfos, enanos, duendes, lutin, kobold, los faunos y silvanos, entre otras entidadades paganas que al final, y con un ánimo satanizador, fueron titulados en las más de las ocasiones como «demonios» (Lecouteux 1998). Tal como señala Covarrubias en su Tesoro, se considera que este ser es un espíritu «de los que cayeran con Lucifer», cuestión negada por Fuentelapeña, pero que se mantuvo en los siglos siguientes.

Como es visible, el cristianismo no acabó con los duendes; estos convivieron con otros seres e intercambiaron de nombres. Incluso se encontraron otras razas en el nuevo mundo. México, por ejemplo, habla de aluxes, balamo'b, chamaquitos, sombrerones, tzitzimimes, xocoyoles, chaneques. Cada uno con sus características diferenciadoras, pero que en ocasiones difícilmente se distinguen o se confunden entre sí ${ }^{5}$.

Ya fuera porque los aluxes o los chaneques habitaran las tierras americanas en el imaginario, ya fuera porque estos migraron en la mente de los conquistadores y viajeros al Nuevo Mundo, lo cierto es que aparecen de manera recurrente en América y en particular en la Nueva España ${ }^{6}$. Así, por ejemplo, Pedro Sánchez de Aguilar, en su Informe contra los idólatras de Yucatán, cuenta, además de asuntos de hechicerías indígenas y algún prodigio de la mentalidad maravillosa cristiana, un caso sobre un duende: «Tampoco vendrá fuera de propósito traer a la memoria cuán perseguida, y alborotada, y escandalizada estuvo la villa de Valladolid [...] con un demonio parlero, o duende (caso estupendo e inaudito) que hablaba»

$5 \quad$ Para el Chaneque y el duende, véase la tesis Personajes y espacios sobrenaturales en la tradición oral de Coatepec, Veracruz (2016), de Adriana Guillén, donde se identifican las diferencias de estos seres en Coatepec, Veracruz y también se señalan las similitudes con sus homónimos europeos. Los duendes parecen tener características diferentes de acuerdo a la zona geográfica que habitan, un ejemplo que se encuentra en Michoacán, ubica muy específicamente a un ser a su zona de origen: el «Duende terracalenteño, parecido a un niño que tiene origen prehispánico» (Medina Pineda 2005: 45).

6 Como señala Luis Weckman «lo que los españoles buscaban en el Nuevo Mundo no fue lo que se antojaba novedoso, sino más bien la confirmación de la existencia de lo maravilloso» (1994: 47). 
(Aguilar 1996: 139). Otros textos de la época suelen introducir también este término en tratados y relaciones, muchas veces como sinónimo de diablo. En realidad parece haber un intercambio de términos por otros que no se entienden, probablemente de seres a quienes los misioneros identificaron así, sin saber a ciencia cierta, y sin darle importancia en el fondo, del tipo de ser al que se referían.

Los expedientes del Santo Oficio de México reiteran motivos recurrentes de la tradición oral hispánica. Se repitió, por ejemplo, la historia del duende que causa estropicios hasta que provoca la mudanza de la familia que lo alberga. Esta da cuenta de la inutilidad de la mudanza en el momento en que escucha al duende asegurar que él se encargó de traer la escoba que olvidara la criada. Se repiten también los tópicos de travesuras, ruidos, golpes y destrozos en las casas; por ejemplo, en 1618, el Santo Oficio de México recibió la carta de don Juan Gutiérrez, quien avisaba que en la «noche le rompían la loza y las macetas a pedradas, le cambiaban los muebles de un lugar a otro, descolgaron un cristo rompiéndole un brazo y tantas molestias que creyendo ser del demonio o de algún duende mudaron de casa y averiguó que quien hacía todo era una negra» (AGN, Inq., 317, exp. 18, f. 1). Otro caso, citado por Javier Ayala (2010: 276), ocurrió en 1685 en Verapaz, donde un duende «tiraba piedras de noche y de día a las casas de Felipe Carcamo». Se culpaba del suceso a un tal Melchor Larios que tenía «mala amistad» con una mujer. Sin embargo, señala el investigador que «el verdadero problema era que - pese a lo fantástico que pueda sonar-, según la familia de la implicada, cada tercer día, y sin importar qué tan custodiada estuviera la muchacha, una fuerza invisible la sacaba de su casa a través de un agujero pequeñito que había en el techo de la cocina y luego la encontraban atada al tronco de un árbol» (Ayala 2010: 276).

Los ataques con piedras cuyo origen era posible averiguar, y las apariciones a hombres y mujeres, con quienes haría amistad de una forma $u$ otra eran motivos recurrentes en este tipo de historia (Ayala 2010: 268-279).

Prevalecen, también, los elementos amorosos que caracterizan a estos personajes. Un ejemplo interesante, citado por Javier Ayala (2010: 273-274), ocurriría a un muchacho de 26 a 28 años, quien en 1676 relataba:

de la persecución que sufría por parte de un duende [...] que durante un tiempo la relación entre ellos había sido tan extremadamente «cordial», que muchas veces el duende se le acostaba en los brazos, dormía con él y, de hecho, hasta habían tenido comercio carnal en el monte, obteniendo con él el mismo deleite que se tenía con una mujer. A pesar de su excitante inventiva, una historia como esta pronto motivó el desconcierto y un profundo desagrado de su auditorio cuando el joven aclaró que la figura del duende solía ser la de un «frailecito pequeño de San Francisco», si bien —insistió - cuando habían sostenido relaciones sexuales siempre había sido con forma de mujer. 
Son más los casos, sin embargo, de mujeres acosadas o atraídas por los duendes. Así, por ejemplo, tomemos el caso con el que iniciamos este estudio, en el cual un fraile reproduce la autodenuncia que hiciera el 15 de mayo de 1716 «María de la Trinidad, natural del pueblo de Opico, jurisdicción de San Salvador, mestiza amulatada, soltera, de edad de veinte años, a lo que parece (que no lo sabe con fijeza), hija de padre no conocido y de María, mestiza, vecina del dicho pueblo de Opico». La confesión se produce en la catedral de Guatemala:

María de la Trinidad, criada, antes, del beneficiado don Antonio Trejo y ahora avecindada en Goatemala, en casa de doña Josepha Trejo - sita al sur, a dos quadras de este colegio, calle arriba de don Joseph Rodesno, a mano isquierda - dice que, en dicha casa de su señora, dio un duende en causar algunas molestias, persiguiéndola con especialidad a ella. Y lo confirma con que, en saliendo ella de la casa, le iba por la calle tirando piedras, sin sentirse perjuicio, dentro, el tiempo que María estaba fuera. Y que sin dar motivo se le dejó ver en hábito de mercedario dos vezes: una por la mañana del día 12 del mismo mez, como a las siete, y otra a la una del mesmo día. Fueron las dos visiones instantáneas, en un pasadiso que ay de el patio de la casa a un corral, donde fueron también las siguientes (Flores y Masera 2010: 224).

El relato de María de la Trinidad se repitió en varias ocasiones en los expedientes inquisitoriales. Bien visto, la narrativa mantiene tópicos y motivos comunes en este tipo de historias; por ejemplo, el motivo de la persecución o seducción del duende a las mujeres. Este motivo se ha repetido a lo largo de los siglos en diferentes relatos literarios que enlazan las razas de los duendes, enanos, elfos. Por ejemplo, Lecouteux menciona que la raíz dhwer(gh), dhvarati, implica noche, prejuicio. Y en este sentido cita las historias de Albán y Laurín, que son raptores, engañadores, cuando no violadores de las doncellas en las obras Orendel y Laurin (1998: 96-97). El cristianismo y sus diferentes autoridades durante la Edad Media y el Renacimiento interpretan a los seres diminutos con súcubos e íncubos, amantes de hombres y mujeres; por su parte, algunos autores del siglo XIX, citan casos en los que los elfos roban a las mujeres. Walter Scott sería uno de ellos:

Un tejedor pierde a su esposa. Ésta muere entre convulsiones y el cadáver está tan desfigurado que las comadres del vecindario piensan que la han velado mal y las hadas se la han llevado y la han sustituido por ese cuerpo. En el momento en que el tejedor está pensando seriamente en casarse de nuevo, su difunta esposa se le aparece una noche y le dice que no está muerta, sino cautiva de los «buenos vecinos» — eufemismo que designa a los enanos_- y que, si todavía la ama, puede hacerla regresar del triste reino de Elfland. Pero el tejedor no hace lo que le pide el «fantasma» (Lecouteux 1998: 193). 
De hecho, señala Lecoteux, entre los seres feéricos cabe resaltar a los lutins, que son los que mejor se ajustan al carácter del genio doméstico desde la Edad Media y cubren con otro de los elementos que se repite en las historias de duendes: la travesura a través del lanzamiento de piedras. «Las pedradas son una de las formas del lenguaje de las almas del purgatorio o de los difuntos sin sepultura», señala el investigador para el caso del personaje doméstico en las crónicas medievales (Lecouteux 1998: 191).

El tópico de lanzar piedras y el vestido del duende son elementos provenientes de la tradición y se repiten en gran parte de las historias de este tipo y ambas son mencionadas por María de la Trinidad en su autodenuncia, quien asegura haber invocado al duende un miércoles al anochecer en el lugar en que se le aparecía comúnmente. Este acudió «en traje de negro horroroso y hechando [sic] llamas» (Flores y Masera 2010: 224). El duende en este momento toma un cariz demoniaco, pues hasta entonces el personaje se había aparecido en «hábito de mercedario», traje que podría no ser del todo inocente. Sabemos que los duendes suelen ser descritos con hábitos de capuchinos o franciscanos; incluso, es así como Cosme lo describe en La dama Duende: «Era un fraile / tamañito, y tenía puesto / un cucurucho tamaño, / que por estas señas creo / que era duende capuchino» (Calderón de la Barca 2000: 209), asegura el criado cuando don Manuel le pregunta cómo era la figura a la que Cosme en realidad no había visto.

Los mercedarios, que es la Orden a la que pertenece el fraile que se describe en nuestro proceso, tenían, a decir de Mariana Masera «fama de lascivos» (León Cázares apud Flores y Masera 2004: 123). Y es que el duende, como el fraile, en muchísimas ocasiones aparece como un ser enamorado, que en ocasiones intenta conquistar, si no es que violar o raptar a las mujeres de las que se enamora.

La asociación del duende con el amor se aprecia con claridad en un romance que se publicó en la séptima parte de la Flor de varios romances, en donde encontramos una estrofa como la siguiente:

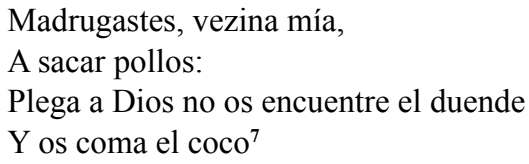

$(N C, 1815)$

7 La frase «sacar pollos» no es tan inocente, pues como informan los editores del volumen Poesía erótica del Siglo de Oro (2000: 75) sería «ocupación inocente cuando se toma al pie de la letra, más peligrosa si se tiene en cuenta el otro sentido, no registrado por los léxicos, de la palabra pollo». 
Que podría interpretarse de manera un tanto inocente, como una evocación de los temores infantiles, ello además se confirmaría a la vista de variantes como las que cita Margit Frenk en el Nuevo Corpus, una de ellas diría: «Madrugasteis a venir, niño, / de noche y solo: / plega a Dios no os encuentre / y os coma el coco» (II, n. ${ }^{\circ}$ 1.815). Sin embargo, también es cierto que estas canciones pueden estar más asociadas con lo erótico: la primera hora del día, el alba se asocia con el encuentro sexual (Masera 2001; Pedrosa 1998). El duende puede llegar a tener connotaciones sexuales, en gran parte debido a que se mueve en lo oculto, en la oscuridad o en alba. María de la Trinidad se lo encuentra a las siete de la mañana la primera vez, más adelante a la 1:00, y en una tercera ocasión ella lo invoca al anochecer de un miércoles.

Otro tópico que también parece asociado al amor es la acción de «tirar piedras». Recordamos que esta costumbre aparece registrada en la caracterización que hace Fuentelapeña del personaje del que, recuerda el fraile, se dice que gusta de «tirar chinas» a las personas, lo que es el equivalente a tirar piedrecillas. Respecto a esto vale la pena recordar un estudio de José Manuel Pedrosa, quien señala que el motivo de tirar frutos, flores y piedras al amante era una forma de cortejo. Pedrosa recupera la explicación que González Correas diera al refrán «si son amores, vengan maiores»; y que el autor glosara remitiendo a sus lectores a la costumbre de «lanzar chinas [...] "u otra kosilla" para llamar la atención de alguien con fines "de amores"». A tal definición Pedrosa (2006a: 97) añade: «Kuando nos tiran china u otra kosilla para que volvamos la cabeza (Correas 1967: 282a)». El sentido que sugieren el refrán y la glosa de Correas parece remitir a la costumbre, sin duda tradicional en la época, de lanzar chinas — piedras pequeñas — «u otra kosilla» para llamar la atención de alguien con fines «de amores». No me extrañaría que este fuera en realidad el motivo que tuviera el duendecillo en la historia contada por la mestiza a la Inquisición de México.

El motivo en realidad sigue apareciendo en otros relatos de duendes, aunque no siempre tiene una función amorosa. En ocasiones pareciera más coincidente con las actitudes juguetonas de los personajes, así se puede apreciar en un relato recogido por Araceli Campos (2007: 72), en el pueblo de Xochimilco, a Silvestre Moreno Romero, quien relataba que los duendes eran «unos niñitos chiquitos y siempre andaban encuerados, andaban por donde íbamos a sacar agua dulce, y cuando nos acercábamos nos aventaban piedras, y nosotros se las regresábamos y así jugábamos».

La aparición del siglo XVIII pareciera tener un carácter lúdico. Se trata de un duende que tira piedras a una muchacha sin que esta sintiese «perjuicio» alguno hasta el momento en el que la denunciante asegura haberlo invocado con ánimos de hacer un pacto. Entonces se reproduce el siguiente diálogo: 
—Sácame de aquí, que no puedo ya más, y te daré el alma.

Respondió él:

- Ten paciencia y te daré gusto.

No ubo más razones entonces. El viernes, desde las sinco de la tarde hasta las ocho de la noche, en el mismo lugar, se le hizo con la misma figura encontradiso. Díjole la primera vez María, de quatro que en el término de esas tres horas lo vido:

— ¿Quándo me llevas?

Respondió el demonio:

-Yo te avisaré.

La segunda vez de éstas, le instó:

— ¿A qué aguardas para llevarme?

Y satisfizo el Demonio:

-Antes de mucho.

Las otras dos veces dice que el duende, en la figura misma y lugar, la llamó con la cabeza, pero, horrorisada, no quiso ir. Con que fueron siete las veces que lo vido y tres las que le habló (Flores y Masera 2010: 224).

Lo que hasta entonces había sido una historia de duendes se transforma en un relato de pactos demoniacos, pues el mismo duende, antes un pequeño ser vestido de mercedario, toma un aspecto terrible. Sin duda esta transformación es significativa. No alcanzo a medir hasta qué punto se refiere al rostro e incluso a la vestimenta. Es evidente, sin embargo, que esta aparición produce temor en la emisora del relato.

Cabe señalar que la muchacha aclara que la solicitud hecha al duende se produjo por las condiciones de vida que tenía en ese momento: «vejada de sus amos e impaciente». Esta situación nos permite entrever una denuncia. Se trata, a decir de Santiago Cortés, de información intersticial secundaria, «un segundo nivel informativo que, a la manera de una caligrafía velada, nos hace imaginar o suponer rasgos de aquel que pronunció esas palabras y de la cultura que poseía y lo poseía» (Cortés 2004: 80). Además, agregaría, de las condiciones de vida y las cuitas en las que vivían los informantes. En este caso, la declaración deja entrever la queja de una mujer aparentemente maltratada, que la lleva a realizar una acción extraordinaria. Como señala Jair Antonio Acevedo:

solicitar ayuda de personajes y fuerzas considerados nocivos por la Iglesia probablemente sólo haya sido fruto de la desesperación, una última opción luego de comprobar que las súplicas eran desoídas por las entidades divinas, pues si éstas no atendían a las personas, sus contrapartes no dudarían en prestarles el socorro que tanto anhelaban (2019: 288).

Tal desesperación se aprecia en la insistencia de la muchacha, quien por tres ocasiones le pide al ser que la lleve. El número puede ser tópico, pero también 
pudo tener una connotación simbólica mágica. Aún así, pareció no dar resultado, tal vez por la seguridad que el personaje tenía sobre la muchacha. Posteriormente, ella afirma haber rechazado al «encontradizo» duende por cuatro ocasiones más, el número siete también parece ser simbólico, no entra en detalles de las razones por las cuales cambió de opinión y afirma que sus condiciones cambiaron cuando se mudaron a otro lugar.

Villa-Flores recuerda también que el Santo Oficio representó durante un tiempo un medio de escape para quienes vivían condiciones opresoras, a tal grado que fueran forzados a blasfemar ${ }^{8}$. Ante estos casos, y siempre que no se tratara de una condición constante, la Inquisición se mostraba indulgente, e incluso llegó a perseguir a quienes provocaban estas reacciones en sus subalternos. Sin embargo, la denuncia de María no parece ser contra sus antiguos amos; más bien, se trata de un descargo de conciencia.

Los elementos que entonces recupera parecen mostrar un encuentro amoroso fallido con un personaje ambivalente. El hecho, sin embargo, de que ella lo identifique con un duende es significativo. El principio de la historia, por otra parte, da elementos para ubicarlo bajo esta denominación. Incluso el diálogo posterior muestra a un personaje juguetón, sin intenciones verdaderamente negativas, aunque sí impredecible.

El detalle que casi pasa por alto, porque apenas se menciona en este proceso, es el hecho del maltrato de la muchacha, vejada por sus amos, acosada por un personaje «sobrenatural». Su desesperación la lleva a optar por un camino que la llevará a la perdición, pero lo prefiere. Ello es, pues, una muestra de las condiciones que vivían muchas mujeres en el Nuevo Mundo. Se trataba de una mestiza amulatada, un sector que no tenía las mejores condiciones sociales. La muchacha, además, tenía veinte años y era soltera, no sabía escribir. Con seguridad, la persecución del duende era un problema menor frente a otros de los que trata de escapar por medios mágicos. El proceso nos permite ver que la muchacha es incapaz de tomar las riendas de su propio destino y de cambiar de vida a menos que un suceso secundario ocurriera, en este caso: «Movió Dios a su ama a que la llevase a San Juan de Dios, de donde vino a confesarse. A pocos días se acabaron del todo las molestias del duende» (Flores y Masera 2010: 224), seguramente también, finalizaron otras condiciones que el expediente no menciona pero que se pueden leer entrelíneas.

La carta concluye con la voz del confesor, Miguel Joseph de Ortega, de la Compañía de Jesús, quien no parece cuestionar el relato de la muchacha, únicamente

\footnotetext{
8 Esto lo muestra en particular un expediente del siglo XVII en el cual se exponen las condiciones infrahumanas a las que fueron sometidos esclavos negros en un obraje (Villa-Flores 2016: 223-246).
} 
se remite a dar cuenta del suceso. En ocasiones parece que lo hiciera de manera textual, palabra por palabra. No es posible saber si su reacción es de credibilidad o simplemente trata de hacer una transcripción literal y objetiva del testimonio escuchado, de manera que su interlocutor pueda aconsejarle respecto a la posibilidad de absolverla. No encontramos la continuidad de este caso y, por tanto, será difícil por lo pronto hablar de su conclusión.

Vale la pena, sin embargo, resaltar la vitalidad de una creencia que migró, con gran éxito cabe decirlo, desde España a América. Los motivos y los tópicos que suelen caracterizar a estos personajes se ven en gran parte de las declaraciones que afirman haberlos visto. Los motivos, por otra parte, se pueden traducir en imágenes recurrentes en el imaginario: duendes, seducción, engaño. El último pudo haber sido el móvil del relato hecho por la muchacha, recordemos que detrás de las historias de duendes también suele haber cierta picardía, oro convertido en carbón y, en el fondo, mucha suspicacia.

La confesión dada a un fraile en un lugar de Guatemala, por otra parte, nos habla también de aquello que no se dice a pesar de su importancia. En este caso una carta habla de una mujer que apela a sus conocimientos mágicos para liberarse de una realidad terrible, o bien, de una mujer que busca despojarse de una culpa de amores encubierta, como muchas otras de la época, y que tan bien fuera retratada por Calderón de la Barca, bajo la capucha de un duende enamorado. En todo caso, de lo que habla es de sometimiento y falta de libertades, ambas retratadas en una confesión y en una obra teatral con un personaje secundario sobrenatural. 


\section{BIBLIOGRAFÍA}

AcEvedo López, Jair Antonio (2019). "Que me quieras/y me ames/y me vengas a buscar»: el conjuro amoroso durante el primer siglo del Santo Oficio novohispano. Una poética de la subversión. Claudia Carranza Vera (dir.) [tesis de maestría]. San Luis Potosí: El Colegio de San Luis.

Alzieu, Pierre, Robert Jammes e Yvan Lissorgues (2000). Poesía erótica de los Siglos de Oro. Barcelona: Booket.

Ayala CAlderón, Javier (2010). El diablo en la Nueva España. Guanajuato: Universidad Autónoma de Guanajuato.

Calderón de la Barca, Pedro (2000). La dama duende. Biblioteca Cervantes Virtual $<$ http://www.cervantesvirtual.com/obra-visor/la-dama-duende--0/html/> [Consulta: $13 / 05 / 2019]$.

Campos, Araceli (2008). «Diez relatos de seres fantásticos en la tradición oral mexicana». Revista de Literaturas Populares, 8 (1), pp. 67-74<http://www.rlp. culturaspopulares.org/textcit.php?textdisplay $=418 \&$ batchdisplay $=>\quad[$ Consulta: $13 / 05 / 2019]$.

Corominas, Joan (1987). Breve diccionario etimológico de la lengua castellana. Madrid: Gredos.

Cortés Hernández, Santiago (2004). «Oralidad y escritura en los archivos inquisitoriales novohispanos: proceso contra el hombre que se volvió toro». En Mariana Masera (ed.), Literatura y cultura populares de la Nueva España. Ciudad de México/Barcelona: Universidad Nacional Autónoma de México/Azul.

Covarrubias, Sebastián de (1994). Tesoro de la lengua castellana o española. Felipe C.R. Maldonado (ed.). Madrid: Castalia.

GuILlÉn OrTIZ, Adriana (2018). Personajes y espacios sobrenaturales en la tradición oral de Coatepec, Veracruz. Claudia Carranza Vera (dir.) [tesis de maestría]. San Luis Potosí: El Colegio de San Luis.

Hernández Sotelo, Anel (2017). «Martinico: la dimensión histórica del duende capuchino en la época moderna». En Claudia Carranza Vera y Claudia Rocha Valverde (coords.), Del inframundo al ámbito celestial. Entidades sobrenaturales de la literatura tradicional hispanoamericana. San Luis Potosí: El Colegio de San Luis, pp. 141-174.

FeIJóo, Benito Jerónimo de (1998). «Duendes y espíritus familiares». En Teatro crítico universal [1729], t. 3. Biblioteca Feijoniana $<$ http://www.filosofia.org/bjf/bjft304. htm $>$ [Consulta: 14/05/2019].

Flores, Enrique y Mariana MASERA (coords.) (2010). Relatos populares de la Inquisición novohispana. Rito, magia y otras «supersticiones», siglos XVII-XVIII. Madrid/Ciudad de México: Consejo Superior de Investigaciones Científicas/Universidad Nacional Autónoma de México.

Frenk, Margit (2003). Nuevo Corpus de la antigua lírica popular hispánica (siglos XV al XVII). Ciudad de México: Universidad Nacional Autónoma de México/El Colegio de México/Fondo de Cultura Económica. 
Lecouteux, Claude (1998). Enanos y elfos en la Edad Media. Francesc Gutiérrez (trad.). Mallorca: José J. Olañeta Editores.

Medina Pineda, Misael (2005). ¡Ah, qué mentirosos son los tiradores! Tradición oral Cutzio-Huetamo. Michoacán: Gobierno del Estado de Michoacán de Ocampo/Secretaría de Desarrollo Social/CONACULTA.

MuÑoz Ledo, Norma (2012). Supernaturalia. Una aventura por la tradición oral de México. Ciudad de México: Altea.

Pedrosa, José Manuel (1998). «El codo ardiente: testimonios de un eufemismo erótico de los siglos de oro». Nueva Revista de Filología Hispánica, 46 (1), pp. 97-103 $<$ https://nrfh.colmex.mx/index.php/nrfh/article/view/2620/2593> [Consulta: $14 / 05 / 2019]$.

Pedrosa, José Manuel (2006a). «Arrojar frutos, piedras, amores: entre la canción y el rito». Revista de Literaturas Populares, 6 (1), pp. 96-127<http://www.rlp. culturaspopulares.org/textcit.php?textdisplay $=360 \&$ batchdisplay $=>$ [Consulta: 13/05/2019].

Pedrosa, José Manuel (2006b). «El ente dilucidado: entre la viva voz y el museo de monstruos». En Antonio de la Peña, El ente dilucidado. Discurso único novísimo que muestra hay en naturaleza animales irracionales, invisibles y cuales sean. Arsenio Lacosta (ed.), Paul Silles McLaney y Maite Eguiazábal (transcrs.). Zamora: Institutos de Estudios Zamoranos «Florián del Campo».

PeÑa, Antonio de la (2006). El ente dilucidado. Discurso único novísimo que muestra hay en naturaleza animales irracionales, invisibles y cuales sean. Arsenio Lacosta (ed.), Paul Silles McLaney y Maite Eguiazábal (transcrs.). Zamora: Institutos de Estudios Zamoranos «Florián del Campo».

Real Academia Española. Diccionario de autoridades $<$ http://web.frl.es/DA.html $>$ [Consulta: 13/05/2019].

Real Academia Española. Diccionario de la lengua <http://www.rae.es> [Consulta: $13 / 05 / 2019]$.

RuBio Tovar, Joaquín (1994). «El imaginario y lo maravilloso en la literatura medieval». Anthropos: Boletín de Información y Documentación, 154-155, pp. 121-124.

SÁnchez de Aguilar, Pedro (1996). Informe contra idolotrum cultores del obispado de Yucatán. Mérida: Instituto Cultural Valladolid.

Weckmann, Luis (1994). La herencia medieval de México. Ciudad de México: Fondo de Cultura Económica/El Colegio de México.

Recibido: $14 / 05 / 2019$

Aceptado: 21/06/2019 
De DuENDES EnAmorados. TRatamiento tradicional DE Un Motivo EN UN CASO RECOGIDO POR EL SANTO OfICIO NOVOHISPANO

RESUMEN: Este artículo repasa la presencia de motivos tradicionales en torno a los duendes, existentes en una autodenuncia realizada en la ciudad de Guatemala en el siglo XVIII. El relato encontrado en una carta dirigida a la Inquisición muestra también la situación de opresión de una mujer mulata en su sociedad, pero también la influencia de un imaginario mágico que fue, por otro lado, bastante recurrente y socorrido entonces y en los siglos anteriores y que sin duda se mantiene hasta nuestra época. Este caso también, según veremos, puede tener cierto grado de picardía y erotismo implícitos, acordes ambos con las descripciones en torno a estos seres sobrenaturales.

PalABRAS ClaVE: erotismo, tradición, duende, Inquisición.

\section{ELVES IN Love. The TRADItional TREATMENT OF a MotiF IN A FILE COLLECTED BY the NEW SPAIN INQUISITION}

ABSTRACT: This analysis studies the presence of traditional motifs around the elves, existing in a self-denouncement made in the city of Guatemala in the $18^{\text {th }}$ century. The story found in a letter addressed to the Inquisition, shows the situation of oppression of a woman in her society, but also the influence of a magical imaginary that was quite strong at that time and in the centuries previous, and also remains until our time. This file also, as we shall see, may have a degree of implicit mischief and eroticism, both according to the descriptions of the supernatural beings.

KEYwords: erotism, tradition, elves, Inquisition. 